\title{
Protecting the environment for the sake of sustainable development from the perspective of implementing social responsibilities of Vietnamese enterprises
}

\author{
Van Anh Thi Duong ${ }^{1 *}$, and Lyudmila Pushkareva ${ }^{2,3}$ \\ ${ }^{1}$ National Economics University, 10000, 207 Giai Phong street, Hai Ba Trung district, Hanoi, \\ Vietnam \\ ${ }^{2}$ North-West Institute of Management, branch of RANEPA, 199178, Sredny prospect VO, 57/43, St. \\ Petersburg, Russia \\ ${ }^{3}$ Saint Petersburg State University of Architecture and Civil Engineering, 190005, 4 Vtoraya \\ Krasnoarmeiskaya, Saint Petersburg, Russia
}

\begin{abstract}
Development society brings many benefits to people and also brings many challenges. Those challenges seriously affect sustainable economic development, the life and health of all people in society. At present, issues that the whole society has been facing are: hygiene, food safety, environmental pollution, new epidemics, and exhaust of natural resources as well as warming up of the earth... To limit and solve the aforementioned issues, it needs close cooperation and support from all people and enterprises. Every individual, every organization is a part of society. The development of each individual and each enterprise is also the development of society and vice versa. The rise of society will also have a positive impact on each member of it. Therefore, enterprises need to raise awareness about sustainable development and act responsibly with the community and society. It is necessary and useful not only for enterprises themselves but also for the whole society. In this thesis, the author focuses on addressing the following issues: Carrying out social responsibilities associated with environmental protection in order to sustainably develop of Vietnamese enterprises, thereby finding the causes and proposing solutions to help enterprises fulfill their social responsibilities and protect the green, clean and beautiful environment in accordance with the standards prescribed by the Law on Environment of Vietnam in 2014.
\end{abstract}

\section{Introduction}

In fact, there are two opposing viewpoints on social responsibilities of enterprises. Supporters of the first point assumed that enterprises do not have any responsibility to society but only to shareholders and employees of enterprise, and the state must be responsible to society; Enterprises have a responsibility to society by paying taxes to the

\footnotetext{
"Corresponding author: anhdtv@neu.edu.vn
} 
state. And the second point is that as one of the subject of market economy, enterprises have used social resources, and exploited natural resources and in those processes, they have been causing harm to the natural environment. Therefore, in addition to paying taxes to the State, enterprises must also have social responsibility for environment, community, and employees.

In other words, enterprises that want to develop sustainably must always follow standards on environmental protection, gender equality, labor safety, labor rights, fair payment of salary, staff training and development and community development. The sustainable economic development will create prosperity for the community and efficiency for all economic activities. The core of economic sustainable development will help all operations of enterprises be sustained in the long term. Simultaneously with sustainable economic development, it is the sustainable social development, which is respect for human rights and equality for all. It requires a fair distribution of benefits, with a focus on hunger eradication and poverty reduction. Recognize and respect different cultures, avoiding any form of exploitation. The sustainable development of the environment must ensure the management and protection of natural resources; minimize environmental pollution, conserve biodiversity and other natural assets.

\section{Sources and research methods}

To complete this thesis, the author's collective uses a combination of methods, such as: survey, statistics, analysis, comparison, interpretation, inductive, etc. on the basis of the sources, which are: Scientific articles of domestic and foreign authors have been published; macroeconomic curriculum; tourism and environment curriculum, Vietnam National University, Hanoi Publishing House and other related documents ... thereby clarifying the social responsibility of enterprises in the sustainable development and environmental protection of Vietnam in the integration period.

\section{Research results}

\subsection{An overview of the environment for the sake of sustainable development from the perspective of social responsibilities of enterprises}

In Vietnam today, social responsibilities of enterprises associated with environmental protection is still a relatively new issue and is understood in many different ways, such as protecting the environment by minimizing pollution during operation; Optimizing the use of resources (Electricity, water, energy ...); Contributing financial, human resources, initiatives and other resources to building an equal and civilized community; Respect the human rights of employees in the company; Fairness, transparency in management and competition with competitors .. .. Since then, maximizing the positive effects and minimizing negative consequences for society. Thus, it can be affirmed that, social responsibility is the duty that an enterprise must perform towards society and must have social responsibility. As for employees, enterprises must consider employees as their greatest assets, take care of their material and spiritual life, ensure that employees not only reproduce labor power, but also are improved professional qualifications, health care for employees,. Thus, in order for enterprises to develop sustainably, their responsibilities must do well on a number of issues, such as: Protect environmental; Contribute to the social community; Fulfill responsibilities with suppliers; Ensure benefits and safety for consumers; Have good relationship with employees; Ensure benefits for shareholders and employees in enterprises, such as: Pay attention to the life and spiritual material for 
employees in enterprises, to poor employees with difficult economic circumstances; Create conditions for stable jobs for employees, pay attention to working conditions for employees (Building houses, kindergartens, health care areas), etc. for employees to have peace of mind to devote labor to enterprises; Ensure the salary, bonus and social insurance regimes for working employees as well as retired employees so that they can have a stable life; Listen to the thoughts and aspirations of employees, regularly hold dialogues with employees to solve problems between enterprises and employees...

Social development brings a lot of benefits to the community, while also bringing a lot of challenges to the society. The whole world is now facing many serious problems, such as: Food hygiene and safety, polluted environment, new epidemics, exhaustion of resources as well as warming process of the Earth. In order to limit and solve the above issues, it is necessary to have the close cooperation and support of all people and enterprises. Every individual, every organization is a part of society. The development of each individual, each enterprise is also the development of society, and vice versa, the rise of society will also have positive effects on each member in it. Therefore, enterprises as well as the community need to raise awareness about sustainable development and act responsibly to society and the community. It is a necessary and beneficial work not only for ourselves but also for the present society and future generations.

- In term of economics: Social responsibility of an enterprise is to produce goods and services meeting best for the society at reasonable prices, to fulfill their obligations with the State, with investors, and with consumers, to seek labor supply, to discover new resources, to promote technological progress, to develop products; to find suitable way for distributing production resources such as goods and services in the social system, to create jobs with worthy compensation, to create equal employment opportunities, to create opportunities for career and profession development and to enjoy a proportional compensation and a safe and hygiene working environment, as well as privacy and personal protection in workplaces.

- In term of legal perspective: Social responsibility of an enterprise is to fully comply with legal regulations for related parties, competitive regulation, customer protection, environment protection, promote fairness and safety and provide initiatives against wrong behaviors. The legal obligations are reflected in civil and criminal law. Basically, legal obligation consists of five aspects, namely: Competitive Regulation; Consumer Protection; Environmental Protection; Safety and Equality; Encouragement of detection and prevention wrong behaviors.

- In terms of ethics: Social responsibilities of an enterprise are behaviors and activities that are expected by the society but are not stated in the legal system, and not institutionalized in law. Ethical aspect of an enterprise is often expressed through ethical principles and values that are respected in mission statement and strategy of enterprises. Through these publications, ethical principles and values become guideline for coordination of actions of each member in enterprises and with stakeholders.

- Sustainable development: Sustainable development is an overall development, covering all issues in a country, such as: Sustainable development of economy; sustainable development of politics; sustainable development of environment; sustainable development of health; sustainable development of education and training; sustainable development of culture, security, national defense ... in this thesis, the author's collective only mentioned the sustainable development of Vietnamese enterprises in production and business activities.

In order for Vietnamese enterprises to develop sustainably in the context of regional and global economic integration, the basic contents of sustainable development include:

- Enterprises that want to develop quickly must go hand in hand with sustainability. Thus, enterprises who want to develop sustainably need to prepare all necessary and sufficient conditions at both macro and micro levels, combining both short-term 
development and long-term development.

- Quantitative growth must go hand in hand with improving the quality, efficiency and competitiveness of the economy.

- When exploiting development factors in width, especially, it must be paid attention to development factors in depth and development of knowledge economy.

- Economic growth must be associated with cultural development, comprehensive human development, implement democracy, progress and social justice, create jobs, improve living standards, encourage legal enrichment in parallel with poverty reduction.

- Must attach importance to environmental protection and improvement right in every step of development.

- Economic development must go hand in hand with ensuring socio-political stability, considering this as a premise and conditions for rapid and sustainable development.

\subsection{The meaning of the implementation of social responsibility associated with environmental protection for the sustainable development of Vietnamese enterprises}

- Performing corporate social responsibility, contributing to adjusting the behavior of business entities: The reality shows that, when well performing social responsibilities, it will improve financial situation, reduce operating costs, improve credibility, have better risk management and crisis management, promote commitment to employees, have good relations with government and the community, increase productivity ...

- Performing social responsibilities to contribute to reducing costs and increasing productivity: Enterprises can only save production costs when they invest, install new equipment, improve product technology. For example, a large packaging manufacturer in Poland saved US \$ 12 million over a five-year period by installing new equipment, thereby reducing water use by $7 \%$ and $70 \%$ of water waste and $87 \%$ of gas waste. On the other hand, production costs and labor productivity depend on the personnel management system. An effective human resource management system also helps enterprises cut costs and increase labor productivity significantly. The salary and bonus regime is reasonable, the work environment is clean and safe. Training opportunities and health and education insurance policies all contribute to reducing the rate of employees leaving and quitting their jobs, thereby reducing the cost of recruiting and training new employees. All the above issues contribute to reducing production costs, increasing labor productivity for enterprises.

- Implementing social responsibility contributes to increase revenue:

Each enterprise has a certain operating area. Therefore, the investment to support local economic development can create a better source of labor, cheaper and more reliable supply sources, which increase the consumption scale, increase sales for enterprises. For example, Hindustan Lever Company, a subsidiary of Unilever Group in India in the early 70s, only operated at $50 \%$ of its capacity due to the lack of supply of cow's milk from the locality and consequently it suffered serious losses. To solve this problem, the company has established a comprehensive program to help farmers increase cow's milk production. This program includes: Training farmers in raising animals, improving basic infrastructure and establishing a committee to coordinate local suppliers, so that the number of localities supplying cow milk has been increasing from 6 localities to more than 400 localities, helping the company operate at full capacity and has become one of the most profitable business branches of the Group. - Performing social responsibility contributes to enhancing the brand value and reputation of the company

The implementation of social responsibility can help enterprises increase the brand value and reputation significantly, from that, it will help enterprises increase revenue, 
attract partners, investors and employees.

- Implementing social responsibilities contributes to attracting good labor resources

An enterprise that owns a good and capable labor force will be the deciding factor of the productivity and product quality of the enterprise. It is a fact that, in developing countries, trained human resources with high quality are not much. The problem for enterprises is how to attract, retain them and promote their best ability in business management and production activities of enterprises. Therefore, attracting and retaining well-qualified employees is a big challenge for enterprises. In the context of a market economy, enterprises pay worthy and fair salary, give employees the opportunity to train, have health insurance and a clean working environment that is capable of attracting and keeping human resources of high quality.

- Implementing social responsibility contributes to enhancing the national image:

Social responsibility is an indispensable and global trend, implementing social responsibility is to increase competitiveness and international integration, without conflict with the economic interests of enterprises. The role of the Government in promoting corporate social responsibility is to create a complete legal environment and an equal playing field for enterprises...

Currently, many large enterprises in Vietnam have realized that, social responsibility and environmental protection in production and business activities have become one of the indispensable requirements for enterprises, because, in the context of globalization and international integration, if enterprises do not comply with the social responsibilities associated with environmental protection, they will not be able to access the world market.

Many enterprises when implementing social responsibility have brought practical results in production and business. A recent survey conducted by the Institute of Labour Science and Social Affairs with 24 enterprises in the two leather and footwear industries shows that, thanks to the implementation of social responsibility programs of enterprises, the revenue of these enterprises increased by $25 \%$, labor productivity also increased from 34.2 million VND to 35.8 million VND / 1 employee / year; The rate of exports increased from $94 \%$ to $97 \%$. In addition to economic efficiency, enterprises also strengthen their reputation with customers, create the attachment and satisfaction of employees with enterprises, attract a highly specialized workforce.

Being aware of the importance and benefits of implementing social responsibility in the context of globalization and international integration, a number of large Vietnamese enterprises, in addition to the responsibility of paying taxes to the state, have registered to implement social responsibilities in the form of commitments to the society in protecting the environment, with the local community where enterprises are located and with employees.

\subsection{Current situations of environmental protection from the perspective of social responsibility implementation of Vietnamese enterprises}

Reality in the world has shown that enterprises perform their social responsibility well; their benefits are not only not reduced but also increased. The benefits that enterprises earned when performing social responsibilities include: cost reduction, sales increase, increase of brand value, reduction of staff turnover, productivity increase and opportunity increase of new markets.

A survey of Social Responsibility and Global Survey was made by Nielsen on Corporate Social Responsibility from February 17 to March 7, 2014, on more than 30,000 online consumers in more than 60 countries across Asia Pacific, Europe, Latin America, Middle East, Africa and North America. Samples were selected by age group, gender for each country based on Internet users, and weighting to represent over users with a 
maximum error of $\pm 0.6 \%$. Nielsen's survey was based on behavior of internet users. Rate of internet usage varies by each country. Nielsen used a minimum reporting standard of $60 \%$ internet penetration or 10 million online users to enter the annual survey. Nielsen's Global Online Survey included belief survey of consumers using global online service which was begun in 2005 .

In recent years, in Vietnam, many enterprises have not taken seriously their social responsibilities. This is reflected on fraud behaviors in business, financial reports, and unsafe labor, poor quality of production and trading, and causing pollution to the environment on purpose. Typically, discharge of untreated wastewater causes serious environmental pollution to rivers and communities of Miwon Company, Hao Duong Leather Company, Viet Tri Paper Company, and Hyundai Vinashin Company (Khanh Hoa), production of foods containing substances harmful to human health, such as soybean containing 3-MCPD substance causing cancer, noodles containing phormol, boraxcontained food, and melamine-contained milk and so on. In addition, the violation of laws on salaries, and insurance and labor safety for employees of enterprises are not rare phenomena, which has been causing pressing in the society.

When all agricultural products, vegetables and fruit, fish meat ... are abused chemicals, preservatives, prohibited substances causing cancer ..., it has brought alarmed and panic to city people. Image of a green vegetable is because of pesticide spray of business grower; meanwhile beds of vegetable grown by farmers are stunted but safe without pesticide. So, I wonder about where conscience of business growers? In fact, They poison themselves, because no one can exist alone in the society and everything has been related to each other. The fight against evil, anti-poisoning behavior of consumers, and poisoning their compatriots has had positive signal recently. However, if enterprises and farmers had thought consequences of today, perhaps, the Vietnamese agricultural products, fruits, and seafood have not lost prestige as now and cancer treatment has not too much complicated with number of cancer patients changing suddenly as well.

Dirty food has been flooding the market, which is challenge of managers and is suffered burden for people. Not only that, water pollution has been alarming. Many rivers are poisoned by direct discharge. Vedan stroke the whole society with consternation when this company has been poisoning Thi Vai River during 14 years. With compensation of 200 billion VND for 7,000 people, it is not anything when comparing to damage that people have been suffering and they have to wait time to solve this serious pollution.

Not only Thi Vai River, but also water sources in basin river of Saigon - Dong Nai has been heavily polluted, which does not reach quality of water surface used as a source of daily water. The main factor influence of this pollution is over 9,000 industrial establishments located scattered and intermingled in residential areas in the Dong Nai river basin. On daily average, the river basin must receive about $48,000 \mathrm{~m} 3$ of waste water from these production establishments, many of which have not had centrally-managed wastewater treatment system, directly discharged into water sources, causing bad impacts to poor quality of water. Not only like that, according to Deputy Director of the Department of Natural Resources and Environment of Lam Dong province, the local annually uses more than 500,000 tons of fertilizer, 3,000 tons of pesticides and residues of these chemicals that all pour into reservoirs, rivers and streams. By the flow, all these dangers will flow into the Dong Nai River.

In addition, deforestation in long time has indirectly caused floods, which more than 25,700 hectares of forest has been lost annually. In the last 5 years, Tay Nguyen has lost 130,000 ha of forest. Tay Nguyen is considered as a green roof and the lung keeping ecological stability for the whole country, but now, only in the rainy season, hundreds of houses have been washed away, crops have been destroyed, and tens of thousands of timber has been drifted at river mouths. 
Who will take responsibility for all of the above mentioned risks, if do not want to say that all enterprises must be aware of impact from their business activities and be responsible for their own behavior before society?

In order to limit and solve the above issues, there must be close cooperation and support from all citizens and enterprises. Each individual and every organization is a part of society. Development of each individual and each enterprise is also development of society, and vice versa, rise of society will also have a positive impact on each member of the society. Therefore, enterprises must raise awareness about sustainable development and act responsibly with the community and society. It is a necessary and useful exercise not only for us but also for the present and future generations.

\subsection{Reasons of this status}

- Awareness of social responsibility in and among Vietnamese enterprises is quite much difference

- Labor productivity is affected when multiple codes of conduct are implemented at the same time, such as: wanting to reduce costs to maximize profits and so it means that costs to protect environment shall be cut.

- Lack of financial and technical resources to implement standards of corporate social responsibility (especially for small and medium enterprises)

- The difference between the Labor Code and Code of Behavior set out by customers, which make confusing for enterprises, such as issue of overtime or union activity.

- Lack transparency in applying corporate social responsibility in fact has been obstructing benefits of potential market for enterprises.

- The inspection, supervision as well as the application of sanctions for enterprises that do not comply with the law on the environment are not fully, transparently and publicly, making some enterprises become greasy or some enterprises use tricks to bypass the authorities or intentionally violate the law because the amount of fines is too small compared to the profits they gain by ignoring the steps to protect the environment...

- Contradictions in regulations of the State, which make application of Code of Behavior not to bring expected efficiency, such as wages, benefits and conditions of employment.

\subsection{Solutions for environmental protection for sustainable development goals from the perspective of social responsibility implementation of Vietnamese enterprises}

To improve the responsibility of enterprises in order to protect the green, clean and beautiful environment to help enterprises develop sustainably, it is necessary to do well some following solutions:

Firstly: Continuing researching, supplementing and perfecting the system of policies and laws on environmental protection, ensuring synchronism and consistency with the legal system in general, sticking to reality and keeping up with the progress of development as well as international integration of the country, rapid changes and complexity level of environmental issues. Paying attention to raising the responsibilities of all levels, branches, enhancing close and synchronous coordination among branches, between the center and localities in the inspection and supervision of environmental protection of enterprises.

Secondly: strengthening capacity of the State management agency in charge of environmental protection from the center to localities to meet the requirements and tasks of environmental protection which is getting bigger and more complex. Reviewing and clearly defining management functions and tasks, organizational structure, and enhancing the 
management capacity of environmental management officials at all levels, especially in localities.

Thirdly: Strengthening and diversifying investment capital sources for environmental protection, especially investment in waste treatment, pollution treatment and environmental restoration in polluted and degraded areas. Increasing budget expenditures for the cause of environmental protection, focusing on solving urgent and long-standing environmental problems..

Fourth: Good implementation of propaganda for enterprises and communities:

Strengthening propaganda and education for all enterprises, and first of all, they are owners of enterprises on corporate social responsibility, which must make them understand that corporate social responsibility is not only in charity action. Propaganda and education are very important, because all human actions are through and driven by their human consciousness. Therefore, the problem is how to make implementation of corporate social responsibility to become internal motivation of business owners. Implementation of corporate social responsibility should first be regarded as a moral act and driven by moral motives. This is the solution within the moral.

Fifth: Building a legal corridor binding enterprises to fully and seriously implement social responsibility:

This involves responsibility of the state in creating environment and legal framework for enterprises to operate. The legal framework is the most effective measure for the implementation of corporate social responsibility; and it is also an effective solution for ethical solutions, making moral motives to be constantly reinforced and increasingly effective in reality. Difficulty for Vietnam and developing countries in general is in the context needing attraction of foreign investment, if pay much attention to environmental and social goals; enterprises are very difficult to attract foreign investment. However, if those corporate social responsibilities are not paid much attention, environmental and social consequences cannot be compensated by results of economic growth. Goal of sustainable development, therefore, cannot be achieved. According to Prime Minister named Nguyen Xuan Phuc, Vietnam cannot exchange the environment for economic purposes. It can be affirmed that the corporate social responsibility is to protect living environment for the society and for the community and it is also goal of sustainable development of enterprises. Therefore, the government must create a legal corridor for enterprises operating in an equal environment that is the path of sustainable development for enterprises.

Sixth: Creating conditions for Vietnamese enterprises to develop sustainably according to the socialist-oriented market mechanism:

Requirements of social responsibility now have become required criteria in business such as SA8000 of textiles. Implementing those standards is a prerequisite for participating in major markets such as the EU, Japan and the US. Practices in enterprises when not being familiar with standards at the beginning are more difficult and confusing, but when putting into operation, these standards also help increase labor productivity and improve product quality, because those standards are very relevant to interests of employees, hygiene of working environment, and labor safety.

Nowadays, regarding to expression through opportunistic forms of a small number of enterprises to be a defect of the market economy, or not, many market economists say that it is not defect of but appears because: (1) the market economy has not fully developed with its full range of mechanisms, institutions, agents and resources (uncompleted and unintegrated law, scattered market, small-scale market, unclear information on market, deep intervention of the Government in the market through administrative orders ...), and (2) together with young market mechanism, it is inaccurate and uncompleted perception (in some cases, it is taken advantaged on purpose for profit) of businessmen and the whole society in terms of business functions and responsibilities. So to address current unhealthy 
phenomenon, the first requirement is to invest in developing a synchronized market economy. A healthy market is a perfect mechanism to identify and exclude tumors.

Thus, the market economy with macro regulation of the State must be implemented in a synchronous, transparent and fair manner with all enterprises and economic components, at the same time, the Government creates all conditions in term of legality for Vietnamese enterprises to self-control in business, in signing contracts, business cooperation in the country as well as abroad. The state does not intervene deeply in operation of enterprises but only managed them through financial instruments, in order for enterprises to have an open and efficient working environment

\section{Conclusion}

Through above analysis, it can confirm that cooperate social responsibility in the current context is necessary and urgent, in term of both theoretical and practical perspective. Although social responsibility of Vietnamese enterprises is relatively new, in recent years, before environmental disasters and negative social consequences caused by enterprises, it has been really an "alarm bell" for society and community as well as enterprises. In Vietnam, implementation of corporate social responsibility is fully consistent with objectives of the sustainable development strategy. Therefore, attention to corporate social responsibility of Vietnam enterprises today must be promoted and considered as a measure of sustainable development of enterprises in the integration period.

\section{References}

1. N. D. Cung, C. M. Duc, Corporate Social Responsibility (CRS): Some theoretical issues and requirements of state reform in term of CRS in Vietnam, Hanoi, (2009)

2. P. V. Duc, Journal of Philosophy, 2 (213), 24-28, (2009).

3. N. N. Phat, Social responsibility of Vietnamese enterprises from a legal perspective, Hanoi, ( 2018).

4. L. D. Doanh, Journal of Philosophy, 3(214), 45-49 (2009).

5. L. D. Doanh, Labor review, 12, 20 - 25, (2018)

6. N. A. Doan : Macroeconomic curriculum, Bach Khoa Publishing House (2006).

7. L. V. Thang; Tran Anh Tuan; Bui Thi Thu, Tourism and environment curriculum, Ha Noi National University Publishing House (2004).

8. KNA Certification Company Limited "Quality innovation": Benefits of implementing corporate social responsibility, Hanoi, (2017).

9. P. T. T. Binh, Sustainable development in Vietnam, evaluation criteria and development orientation. Hanoi, (2014).

10. D.A. Pletnev, V.I. Barhatov, Procedia - Social and Behavioral Sciences. 22, 185-193 (2016). 